\title{
Editorial Note: The intersection of child and women's rights
}

\author{
WENDY HARCOURT
}

Since the 1990s, human rights has become one of the main pillars of development thinking and policy with the shift from assistance and charity to a broader, more political, struggle around people's rights to freedom to live a dignified and fulfilling life. The women's rights movements around the world have been at the forefront of this shift in the fight to make women's rights a human rights issue and to break down the power structures that discriminate against women. The child rights movement has added its own voice strongly in the last decade. However, even given major legal and political recognition of women's rights, and today's strong focus on child rights, growing income inequities, poor access to resources and deeply engrained gender biases prevent women and children from enjoying full economic, social and political rights. This edition of Development aims to explore how the women's rights and child rights movements could best confront this situation by looking at what these two movements can offer each other.

One of the critical lessons learnt by the women's rights movement is that the fulfillment of women's rights does not mean just adding in women alongside men. It requires deep and profound changes to society on all levels. These are political, cultural and social changes that not all individuals, men and women, or institutions are ready to make. To change the discourse of the 'other' is complex. Women have long argued that women should not be defined in some universal sense as only mothers, wombs, breast milk providers, wives and grandmothers. They need to be seen as diverse people ethnically, racially, culturally, with working lives, joys and pleasures, desires and needs within and outside the home and community as they carry out their nurturing and caring function. The women's rights movements worldwide ask for conditions that ensure women's own autonomy and livelihood, as well as the conditions for them to take up their responsibilities towards children and adults of all ages in their care. A lot can be learnt from the various women movements' painful 
attempts to fight the prejudices, even within the movements themselves, which prevent the fulfillment of those sets of rights.

As past issues of Development have documented, even as the rights framework is adopted on paper the cultural, economic and political realities can prevent the conditions for the rights to be respected, protected, promoted and fulfilled. For example, women's reproductive rights were firmly embedded in the agreements reached during the International Conference on Population and Development in 1994. But in order for these rights to be put into practice, there is a need for major shifts in allocation of resources to education and health institutions as well as retraining of medical and family planning staff at all levels. Instead, governments are cutting funds in these areas in an effort to comply with the economic stringency measures imposed by the IMF and by the need to compete in the world market.

What the history of the women's rights movements shows is that individual rights, responsibilities and accountability to self, family and community depend on the broader economic and political environment. To recognize women's rights as human rights requires the political courage to challenge the prejudice and blindness of social, cultural and economic institutions in order to ensure that not only basic needs are met but that wellbeing, respect, dignity and choice feature in everyone's life. The right for women to work with dignity, with fair wages, child care and free from sexual harassment in factories in free trade zones has required a complex set of strategies from women across geo-political divides within UN, government and civil rights movements. The right for sex workers to work in healthy conditions with respect and freedom to move is an on-going struggle engaging national and international women's movements. The right for poor rural women to have information on reproductive rights and proper medical and health care continues to be a right that is, even if promised, not fulfilled.

These struggles are perhaps even more complex in the case of extending economic, social and political rights to children. How do you deal with a child's right to be educated when the child has to work ill health, or worse, because the child is the only one who can find paid employment? The economic, political and social changes needed to grant such children rights - to stop working, to be educated, to be healthy - is difficult enough to fulfil. But when you start to add the right to participate in decision making, to be empowered within themselves, within their family, the community issues become even more thorny. Does an adolescent sex worker have the right to work if she or he wants? Does a child factory worker have the right to fight for better conditions when he or she is illegally employed? Does a mother of 12 have the right to decide on issues that determine her own child's security? Does a child soldier have the right to bear arms?

To tackle the issue of children rights, as with women's rights, it is necessary first to consider children as the subjects of development, not just the objects. First, girls and boys have very different experiences even before they are born. Then there is no universal child just as there is no universal woman. Their age, their education, their economic conditions, the history and culture of their community, their capability to survive, to grow and learn, these are all going to mean different strategic approaches for the fulfillment of their rights.

Just as women have come to perceive that it is necessary to take into account social, cultural and economic differences in order to achieve rights beyond the agreements at international and state level, so do children's rights groups need to find the various strategies and strengths of the child rights movement. Women's rights groups need to support child rights movements in their struggle for rights based on the real world in which they live (of work, of war, of destitution) and child rights movements need to see how gender equity is integral to their own goals.

Most of all, child and women's rights need a change in political will and very different development priorities than the ones we see today. To give the most marginal and vulnerable economic, social and political rights means a very different sort of politics than the traditional notion of benevolent governance. To begin with, it means turning around many of the deeply rooted cultural assumptions about age, gender and identity that are, almost unwittingly, written into development practices. 
It is assumed that women and children, as 'the poorest of the poor', are dependent on the men in their lives, rather than actors who ensure their own livelihoods. The assumption is that they are the recipients of development that need sustenance and protection - aid, education, welfare, health services. They enter as economic subjects only in cases of dire need and as political subjects only rarely, and, if then, largely at the community level. The reality is that most poor women and children have to work for their family to survive. The reality is that they do not have the opportunity or the time or the training or the skills to participate in decisions that affect their lives intimately. Not necessarily because they do not know what they want or would like but because their views are not considered as being part of a political arena. They do not have the power, the clout, to count.

A rights framework tries to bring women and children into the political arena that determines their economic and social rights. But in so doing it is important not to lump women or children into homogeneous groups. Nor is it possible to assume that rights are universal and can be applied to all in the same way. There is a very fluid and unpredictable interpretation of rights in different cultural, political and economic contexts. Women and children living in dire poverty do not have the same capacity to exercise rights as women and children in other economic and social contexts. The rights of a woman or a child in the USA, Sri Lanka, Tanzania and China, for example, are not equivalent. Rights per se do not restrict the power of dominant groups, nor necessarily balance the interest of the individual with the community or the state. What this Development issue highlights is the many different strategies adopted by the women's and child rights movements to contest dominant power structures in the struggle for their rights within the larger struggle for economic survival.

In Jamaica, Janet Brown illustrates the cultural discomfort of Jamaican parents with the concept of rights, which seems to contradict the notion of good manners and obedience and with the necessity to just get on and survive in trying economic circumstances. In Nicaragua, Julie Cupples shows how the appalling conditions of poor women and children, including violence and sex abuse, blurs adult and child lives, making women feel less responsible for their children's rights in the effort to survive. In Zimbabwe, according to Saliwe M. Kawewe, the survival strategy of women has been to fight for the rights of their children to health and education, often to the detriment of the women's own needs. Susan Bissell in her exploration of the intersection of child and women's rights in Bangladesh shows how the best interests of the child have to be understood in the totality of their lives, particularly as many children are the breadwinners in very poor families. Andrea Bosch in her discussion of education and rights for girl children, in particular, also underlines the need for a holistic and realistic approach to children's rights to education, arguing for multi-channel learning that relates to the working lives of children and for gender equity to be part and parcel of childhood development. The description of SOS in Bolivia by Nancy Ardaya Salinas and Claudia Schachinger underscores the need to respect the dignity and rights of both children and women in very poor and fragmented communities. Peggy Antrobus, writing about the small island states in the Caribbean, shows how economic globalization has squeezed out rights, and has led to the coming together of the women and children's movement to fight for their economic well-being as a right. Devaki Jain in her reflections argues that child rights are not possible if women are not seen as agents of development, particularly in cases of the very poor homeless families. Jan Hammill's analysis of the damage to Indigenous women and children if rights are not extended even in wealthy countries like Australia shows clearly how the lack of rights for women is closely linked to spiraling poverty, violence and despair for children.

Looking at the experience of people on the ground it is clear how child rights and women's rights movements need to come to together. The other concerns discussed in the journal - breast feeding, child care, gender marriage gaps - clearly focus on the intersection of the two sets of rights. They discuss openly the tensions and even the apparent contradictions that need to be resolved. Judith Evans, Savitri Goonesekere, Joan French and Bernard Combes bring out even more clearly the links in their examination of two conventions - the 
Convention of the Rights of the Child (CRC) and the Convention on the Elimination of All Forms of Discrimination Against Women (CEDAW).

The strong message of this issue is that women's rights and child rights have to be considered together within a nuanced political and cultural context that uses both the CRC and CEDAW as critical frames of reference. The pressing question now is how these rights are actually to be realized given the current negative economic trends for most of the global South, in particular for the women and children who make up the majority of that world. Major changes are needed in the broad economic global power structure: a task that calls for sophisticated strategic alliance building that respects and responds to the multifaceted realities of poor women and children. It is just such alliances as the Global Movement for Children and the work around the UNGASS on Children to be held in September 2001 that we hope this Development issue can support.

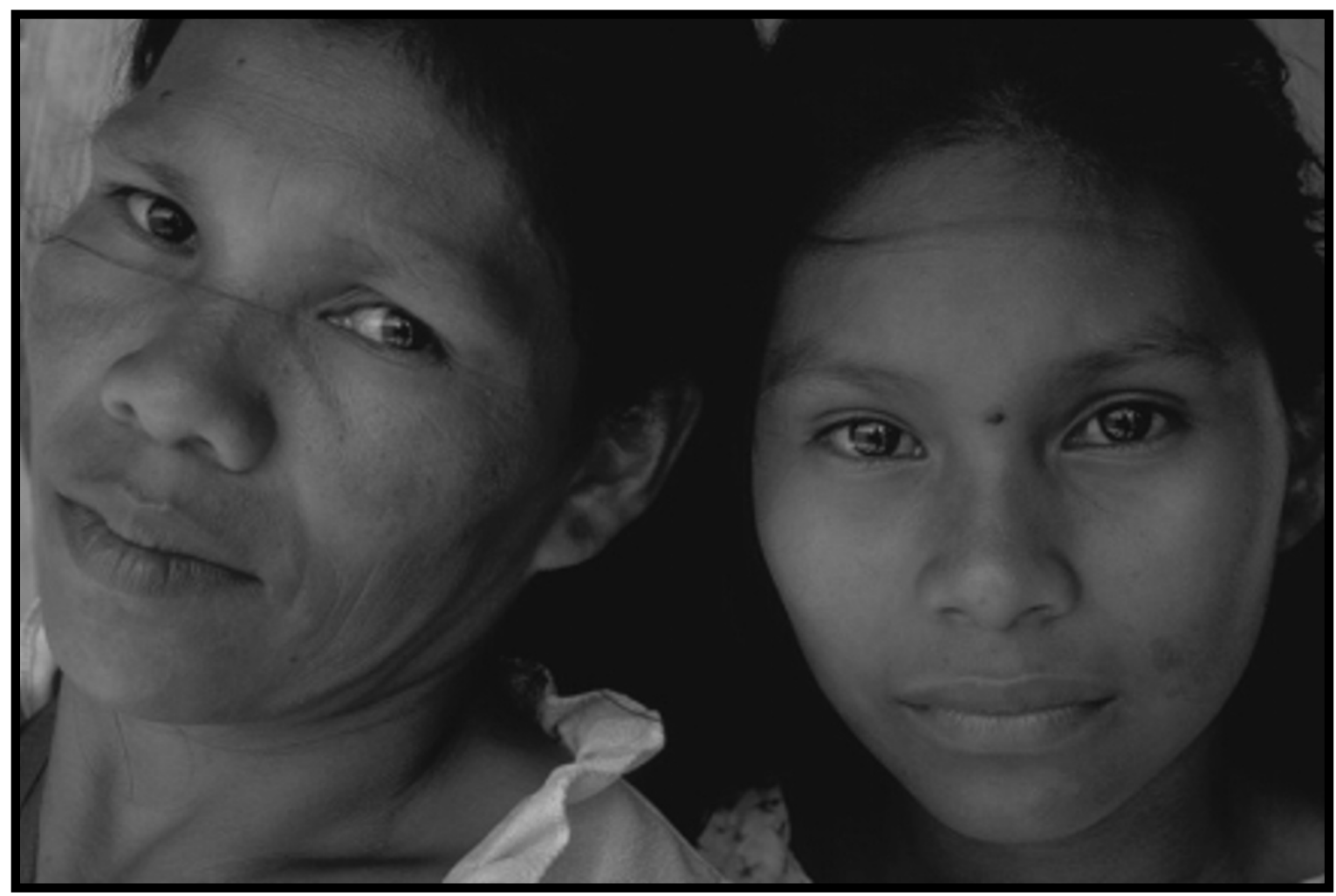

Indigenous rights UNICEF/HQ94-0966/JEREMY HORNER

An indigenous woman and her daughter in the town of Puerto Narino, in the department of Amazonas, Colombia.

Development is abstracted in Cab Abstracts, Communication Abstracts, Environmental Abstracts, GEOBASE, Geo Abstracts: Human Geography, HRI Reporter, International Development Abstracts, International Labour Documentation, International Political Science Abstracts, Social Services Abstracts, Sociofile and Sociological Abstracts; and is indexed in CSA Political Science \& Government, Econlit, Environmental Abstracts, International Bibliography of the Social Sciences, Journal of Economic Literature, OCLC Public Affairs Information Service. 